\title{
Service-Led Model for the Activation of Smart TV: Case Study in Korea
}

DOI: 10.12776/QIP.V23I3.1299

Insu Cho, Jong H. Lee, Young H. Kwak

Received: 29 August 2019 Accepted: 29 September 2019 Published: 30 November 2019

\begin{abstract}
Purpose: This study explores the characteristics of STV service to empirically examine effects of the services on adoption and usage of STV to lead sustained growth of the STV industry.

Methodology/Approach: This study employs structural equation modeling as a quantitative approach, to examine causal relationships between service characteristics and user intentions. The survey collects 212 data only from actual users of STV, who have experienced STV functions or services, in South Korea.
\end{abstract}

Findings: The results of service-oriented model based on extended Technology Acceptance Model (TAM) indicate that 'interactivity', 'content quality', and 'simplicity' as service characteristics influence intention to use STV.

Research Limitation/implication: First, the STV industry should establish a distribution structure that generates sufficient profits for content providers as done in Smartphone market. Second, Services of STV should be provided to allow two-way communication and to allow users to engage in active interactions with other users.

Originality/Value of paper: This study makes contributions to research on both new products and service adoption by providing richer explanations of the mechanisms acting on the actual use of STV. Given that STV is considered a key appliance for the next generation of social media and smart appliance, our findings offer new directions on how to realize high quality services in the STV industry.

Category: Research paper

Keywords: smart TV services; service-led model; extended TAM; interactivity; content quality 


\section{INTRODUCTION}

Smart TV (STV) is changing the IT and media industry and improving consumers' lifestyle by promoting home comfort, convenience, security, and entertainment (Yu, Hong and Hwang, 2016). For example, STV can provide the consumers to access online content such as news, weather forecasts, and map, as well as to use various application services such as social networking services, games, online streaming services (e.g. YouTube) and video on demand (VOD) services (Park and Kim, 2016). Bae and Chang (2012) expected STVs will become a smart hub at home by linking smartphone, handheld devices, and computers and controlling electricity, temperature, home security, and other home entertainment systems. With these advantages, STV has become the main device of smart home, expecting rapid market growth (Bae and Chang, 2012).

Previous studies expected the STV industry to be very attractive (Park and Kim, 2016). In the U.S., BI Intelligence estimated that around 25 million STVs will be active in American households by 2016 (Hoelzel, 2014). In Korea, according to Korea Telecom, STVs account for more than $50 \%$ of the entire TV market share in 2015 (Park and Kim, 2016).

However, the actual growth of the STV industry has been relatively weak. The main reasons for this situation is that many consumers are still using the STV primarily as a substitute of a conventional TV (Grobart, 2013). In other words, because of the lack of useful and valuable services that reflect the features of STV, users do not use various services of STV fully (Yu, Hong and Hwang, 2016). STV manufacturers are trying to develop and explore the services that pull sustained growth of STV industry. These situations imply the needs to move from product oriented view to service-led model for STV industry (Vargo and Lusch, 2004).

Therefore, there is a need to examine current STV services to identify which service factors can provide differentiated values for STV service industry. The objectives of this study include; to analyze characteristics of STV services and extract the important factors different from conventional TV, to develop serviceled model based on extended TAM and service factors, to give implications for activation of STV service industry based on empirical evidence.

The study results and recommendations will help to better understand the consumers' psychological and behavioral intentions about current STV services and provide strategic insights on how to realize high quality services for STV industry. 


\section{THEORETICAL BACKGROUNDS}

\subsection{Concept of Smart TV (STV)}

STV services can provide more customized and interactive experience to users with a wide range of services, including high-quality telecasting contents, twoway communication, information retrieval, Internet shopping, online games, and linkages with other smart devices (Kim et al., 2012). Yu, Hong and Hwang (2016) described STV as a TV set with built-in internet access, based on operating system (OS) that not only provides the broadcasting function of conventional TV but also application stores, searching, game and SNS service. Park and Kim (2016) defined STV as smart media with OS and CPU on a digital TV platform, offering existing broadcasting, VOD, SNS, home network access, and other applications from app store. STV can display broadcast programs from traditional broadcasting channels as well as content from the Internet, so that both sources can be equally used as suppliers of information (Murschetz and Evens, 2013).

STV and smartphone as convergence devices are similar in services and functions, pursuing one source with multiple uses. However, in case of smartphone, the focus is 'communication with others' where users are inclined to 'lean forward' to actively use various applications and contents (Shin, Hwang and Choo, 2013). As a result, smartphone application ecosystem has been well established to lead the diffusion of smartphone as the main mobile device.

Whereas STV is used primarily for watching various contents, so users are inclined to 'lean back' (Yu, Hong and Hwang, 2016). STVs are based on wide screen and high-definition compared to smartphone devices can provide better user experience in certain services such as video streaming and gaming. However some STV manufacturers such as Samsung and LG electronics had challenges regarding software capabilities and content delivery systems to attract their consumers with these STV advantages. As such, they are seeking partnerships with movie studios, entertainment companies, and other content providers to deliver valuable contents (Shin, Hwang and Choo, 2013).

\subsection{Extended Technology Acceptance Model (Extended TAM)}

The technology acceptance model (TAM) has been widely applied in many previous researches to predict and explain end-user acceptance of products or services using new information technology (Davis, 1989). The TAM suggests that user acceptance has three factors: attitude toward using, behavioral intention to use, and actual use (Davis, 1989). The TAM posits that behavioral intention is influenced by two beliefs: perceived usefulness and perceived ease of use. According to TAM, beliefs in new products or services influence attitudes toward using; in turn, the attitudes generate the intention to use. This intention can lead to the actual use of new products or services (Cheng and Yeh, 2011). 
The TAM has been extended and modified in various applications (MartínezTorres et al., 2015). When applying the original TAM to new products and services that offer entertainment, such as smart phones, SNS, or mobile games, new factors are needed to reflect the hedonic value in addition to perceived usefulness and perceived ease of use.

According to the motivation model of TAM proposed by Shang, Chen and Shen (2005), perceived usefulness could serve as extrinsic motivation via the performance of an activity, whereas intrinsic motivation encompasses perceived fun, playfulness, and enjoyment. In research on the user acceptance model of hedonic information systems, Van der Heijden (2004) added perceived enjoyment to the existing TAM. Cheong and Park (2005) also used the concept of perceived enjoyment to investigate user acceptance of the mobile Internet, and Shin (2009) added perceived enjoyment to TAM to better reflect Internet protocol television (IPTV).

Given that STV is Internet connected device as well as family or group-oriented device, STV is likely to evolve as a social platform that have social influence. Social influence used in theory of planned behavior (TPB) (Ajzen, 1991) and unified theory of acceptance and use of technology (UTAUT) (Venkatesh et al., 2003) plays an important role for user's intention or behavior to use new product or service. In social service context, most users may be conscious about what other users think about the technology service, asking their opinions and monitoring their behavior (Shin, 2009).

\subsection{Conceptual Framework Based on Single-Context Theory Contextualization}

This sub-section describes how TAM is modified in this paper based on STV contexts and how the antecedents of TAM are chosen and integrated to the model. This study applies single-context theory contextualization to propose the research model based on extended TAM (Hong et al., 2013). It typically starts with the identification of general theory such as TAM, and then goes through two-step process of contextualized modification to develop a conceptual model. The modification is described as follow:

First step of contextualization is editing a general model by adding or removing core constructs (Hong et al., 2013). First, with regard to the original process (perception-attitude-intention) of TAM, many TAM-related studies have removed the attitude construct to simplify the model. The present study also excludes this construct. Thus, we propose a direct effect between perception and intention. Next, as mentioned in section 2.2, perceived enjoyment and social influence are added to original TAM. Therefore, after first level of contextualization the model remains with perceived usefulness, perceived enjoyment, and social influence as core constructs and intention to use as dependent variable. According to previous research, these variables have consistent impact on innovative products or services (Bere, 2014). 
Second step of contextualization is to add contextual variables as previous factors of core constructs or dependent variables. These contextual variables as external factors generally include system characteristics, service characteristics, and personal traits (Wixom and Todd, 2005). For this research, we extracted interactivity, content quality, and simplicity of the STV services as the antecedent of constructs of extended TAM. The interactivity is extracted to measure how much the consumers become to lean forward due to interaction services provided by STV. We also extracted content quality to measure the value of STV provided differentiated and valuable service. Lastly, we extracted simplicity that may be understood as a lack of complexity when they interact with STV services. Simplicity is based on the concept of perceived ease of use from TAM.

\section{RESEARCH MODEL AND HYPOTHESES}

This section proposes the service oriented research model and develops the hypotheses to identify antecedents of intention to use STV as shown in Fig. 1.

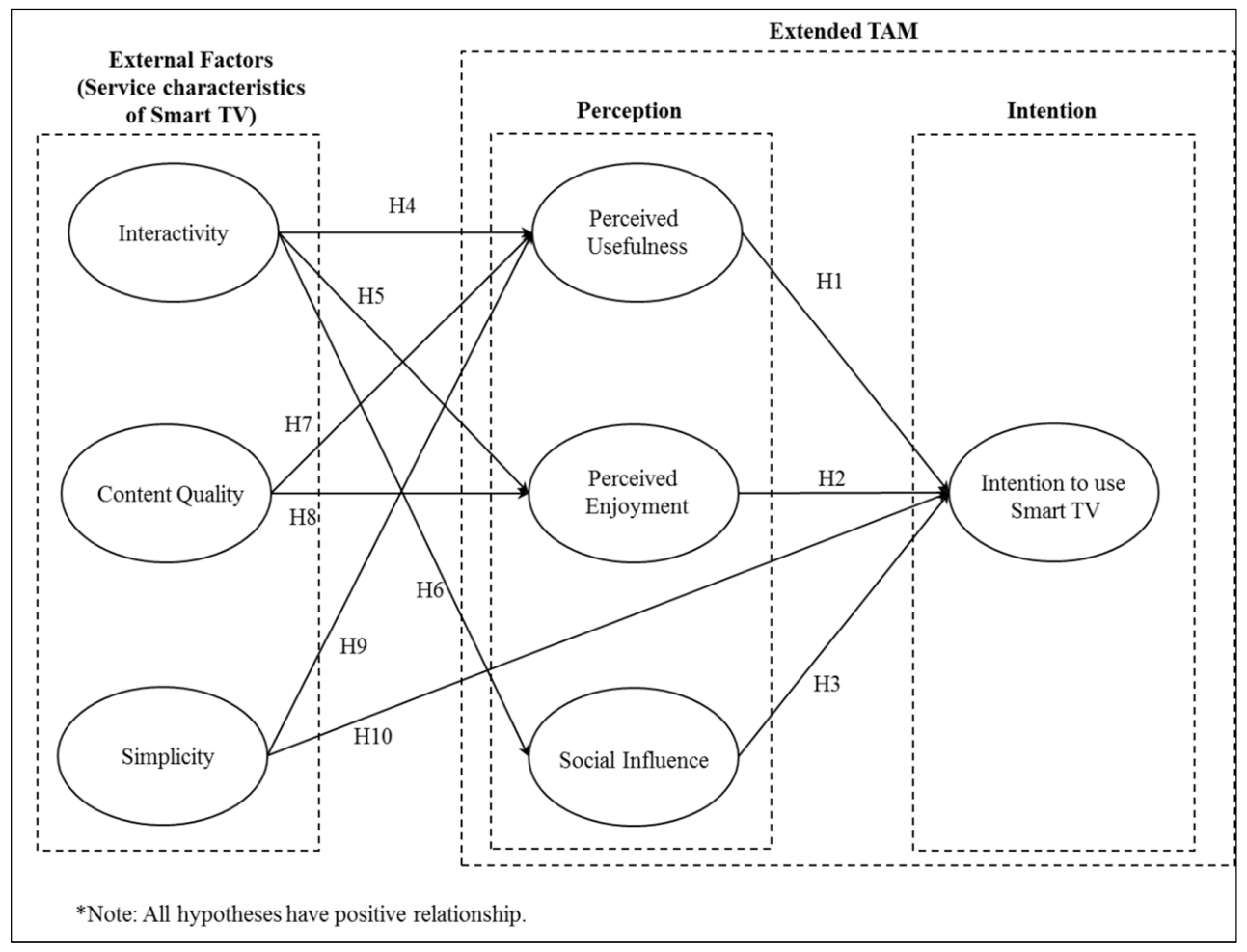

Figure 1-Research Model

Perceived usefulness is defined by Davis (1989) as "the degree to which a person believes that using a particular system would enhance his or her job performance". STV service may support users to reach their goals in everyday 
life. Thus, we propose perceived usefulness, defining as the perception that using STV could help consumers' everyday life.

According to TAM, this variable increases the intention to use a new technology in both voluntary and mandatory contexts (Venkatesh et al., 2003). Kim and Oh (2011) also identified that when consumers have little information regarding new services, they would rely on utilitarian value derived from the services. Then perceived usefulness is strongly related to adoption intention toward new services. In research on IPTV, a context similar to that of STV, perceived usefulness had a positive relationship with intention to use IPTV (Shin, 2009). Also, Lucia-Palacios, Përez-Lõpez and Polo-Redondo (2016) identified the positive relationship between perceived usefulness and google drive usage intention as cloud services. Hence, it can be hypothesized that perceived usefulness has a positive impact on intention to use STV.

\section{H1: Perceived usefulness has a positive effect on intention to use STV.}

High-technology appliances serve practical purposes as well as hedonic purposes (Van der Heijden, 2004). STV as a high-technology appliance can be seen as a hedonic system, as it provides entertaining contents. In the STV context, perceived enjoyment is defined as the degree to which the activity of using STV is perceived to be enjoyable and playful in its own right (Martínez-Torres et al., 2015). Perceived enjoyment is argued to be an important determinant of the intention to use when using advanced products or services for hedonic purposes (Gao, Li and Luo, 2015). Based on an analysis of mobile services (communication, online bill payment, and gaming), which are similar to the services offered by STV, Zhou (2013) proposed that people's intention to continuously use mobile services is directly influenced by the level of perceived enjoyment. In addition, research on the acceptance of IPTV, a forerunner of STV, showed that hedonic motivation is a significant predictor of the intention to use IPTV (Shin, 2009). Thus, people use STV for entertainment purposes.

\section{H2: Perceived enjoyment has a positive effect on intention to use STV.}

Social influence from other technology adoption theories such as UTAUT (Venkatesh et al., 2003) and TPB (Ajzen, 1991) is defined as the degree to which a person has the impression that others who are important to him or her believe he or she should use STV. This implies that the person's intent is influenced by others' opinions and behavior with regard to STV. In the IS perspective, intention to use mobile services is positively effected by social influence (LuciaPalacios, Përez-Lõpez and Polo-Redondo, 2016). In addition, some studies consistently indicate that social influence is an important factor that affects an individual's intentions or behavior (Venkatesh et al., 2003). Therefore, the following hypothesis is proposed.

\section{H3: Social influence has a positive effect on the intention to use STV.}

Interactivity can be defined as degree to which STV can allow consumers to interact with other users in real time, which is the major benefit of STV services 
that conventional TV lacks (Shin, Hwang and Choo, 2013). Also, viewing content and programs on STV, the consumer may use real-time two-way communication through certain services such as chat rooms and bulletin boards. Cesar and Chorianopoulos (2009) explored how viewers interact with TV contents. They identified that viewers react emotionally to TV contents to share and discuss opinions with friends in real-time. It means that a consumer can interact with other users by accessing online in STV (Kim, Ahn and Hong, 2010). A study of American mobile internet users showed that $86 \%$ of the users share their opinions about TV programs that they are watching (Hodgkins, 2011). These interactive activities may increase postivie perception about utility, sociality, and enjoyment (Shin, Hwang and Choo, 2013). Especially, viewer participating content such as game, quiz, and debate can increase not only enjoyment but also social influence.

Consumers can connect their smart device such as smartphone and handheld devices with STV. We called it 'N-Screen service' that enable users to transfer content freely among devices (Yu, Hong and Hwang, 2016). These services are possible to induce active use of STV by making users 'lean forward' to STV with diverse and personalized contents (Briel, 2012). Moreover, these advantages allow consumers to recognize that STV is useful, enjoyable, and social. Therefore, we propose the following hypotheses.

H4: Interactivity has a positive effect on performance expectancy.

H5: Interactivity has a positive effect on social influence.

H6: Interactivity has a positive effect on hedonic motivation.

In digital platforms such as STV, valuable digital content important for product or service market promotion (Yeh, 2015).

Based on the suggestion of DeLone and McLean (1992), our research employs content quality as characteristics of STV service. The concept of content quality is similar to that of information quality as defined by Lin and Lu (2000), given that information in the context of information system is often regarded as content in the context of STV.

On the basis of this concept, content quality refers to the degree to which people can access and customize the content and applications they want through STV. Apart from existing online-based content such as live programs and VOD services, STV can provide new types of online-based content for communication, information, entertainment, and commerce with wide, big, and high-definition screen (Yu, Hong and Hwan, 2016). With information technologies that is now providing various types of content and ways to customize the content, high quality of content positively affects perceived usefulness (Tsai and Chang, 2013) and it makes users more to enjoy and play with better user experience (Shin, 2009). Therefore, high content quality will have a positive impact on perceived usefulness and perceived enjoyment. 
H7: Content quality has a positive effect on perceived usefulness.

H8: Content quality has a positive effect on perceived enjoyment.

In the STV context, simplicity refers to the degree to which the various services of STV are easy to understand and to use with a remote controller (Sonnenwald, Maglaughlin and Whitton, 2001). This concept is related with usability issues such as user resistance which arises in the process of adopting new products or new services. Users will be inhibited to use new products or services if they find it requires more mental effort and time (Al-Jabri and Sohail, 2012). In mobile payment services, Mallat (2007) found that complexity caused by mobile device features such as small keypads has inhibited usability of mobile technologies.

On the contrary to complexity, simplicity of service interface allows successful implementation of communication with STV and therefore decreases the risk involved in the adoption decision (Premkumar and Roberts, 1999). Because STV services use a more complex system than conventional TV, simple interface of services may be more important for usefulness and intention to use (Abroud et al., 2015).

There is considerable amount of empirical research on relationship among ease of use as simplicity, perceived usefulness, and intention to use. Ha, Yoon and Choi (2007) identified that ease of use has positive influence on attitude to use and usefulness of mobile game under mobile broadband wireless access environment. Lee, Cheung and Chen (2007) searched that ease of use as extrinsic motivation positively influences both usefulness and behavior intention to use multimedia messaging services.

Therefore, we infer relationship among simplicity, perceived usefulness, and intention to use.

H9: Simplicity has a positive effect on Intention to use STV.

H10: Simplicity has a positive effect on perceived usefulness.

\section{RESEARCH METHODOLOGY}

We developed measurement items to measure the constructs and examine the research model. All measurement items were developed based on previous findings. The constructs and their measurement items are presented in Tab. 1. Each item was operationalized using a five-point Likert scale ranging from strongly disagree to strongly agree. 
Table 1 - Measurement Items

\begin{tabular}{|c|c|c|}
\hline Construct & Measurement item & Reference \\
\hline Intention to use & $\begin{array}{l}\text { 1. I intend to continue using STV } \\
\text { 2. I intend to use the various functions and } \\
\text { services of STV as much as possible } \\
\text { 3. I recommend others to use STV }\end{array}$ & $\begin{array}{l}\text { Shin (2009), } \\
\text { Shin, Hwang and Choo (2013) }\end{array}$ \\
\hline $\begin{array}{l}\text { Perceived } \\
\text { usefulness }\end{array}$ & $\begin{array}{l}\text { 1. Using STV services is very useful to my } \\
\text { life in general } \\
\text { 2. STV is helpful to achieve my purposes } \\
\text { in general } \\
\text { 3. Using STV would make me more } \\
\text { effective in my life } \\
\text { 4. Using STV can provide useful } \\
\text { information }\end{array}$ & $\begin{array}{l}\text { Verkasalo et al. (2010), } \\
\text { Wu and Wang (2005) }\end{array}$ \\
\hline $\begin{array}{l}\text { Perceived } \\
\text { enjoyment }\end{array}$ & $\begin{array}{l}\text { 1. STV services are entertaining } \\
\text { 2. STV services are pleasant } \\
\text { 3. STV services are exciting }\end{array}$ & Van der Heijden (2004) \\
\hline Social influence & $\begin{array}{l}\text { 1. People important to me think I should } \\
\text { use STV } \\
\text { 2. People like me are expected to use STV } \\
\text { 3. People I look up to expect me to use } \\
\text { STV }\end{array}$ & $\begin{array}{l}\text { Verkasalo et al. (2010), } \\
\text { Shin (2009) }\end{array}$ \\
\hline Interactivity & $\begin{array}{l}\text { 1. Viewers have two-way communication } \\
\text { with the content provided by STV } \\
\text { 2. Viewers can communicate with other } \\
\text { people viewing STV } \\
\text { 3. Viewers can share information and } \\
\text { content with other people }\end{array}$ & Shin, Hwang and Choo (2013) \\
\hline Content quality & $\begin{array}{l}\text { 1. STV provides various information and } \\
\text { services } \\
\text { 2. The service and information I can get } \\
\text { from STV are valuable } \\
\text { 3. STV provides the services and } \\
\text { information that I need }\end{array}$ & $\begin{array}{l}\text { Shin (2009), } \\
\text { Lin and } \mathrm{Lu}(2000)\end{array}$ \\
\hline $\begin{array}{l}\text { Simplicity } \\
\text { (Perceived } \\
\text { ease of use) }\end{array}$ & $\begin{array}{l}\text { 1. I would find it easy to find information } \\
\text { using STV services } \\
\text { 2. It would be easy for me to become } \\
\text { skillful at using STV services } \\
\text { 3. It is easy to use STV services }\end{array}$ & Wu and Wang (2005) \\
\hline
\end{tabular}

We conducted a web-based survey and a paper-based survey in April 2017 and collected data only from actual users of STV, who have experienced STV functions and services, in South Korea. A total of 212 complete and valid responses were collected. For a web-based survey, we accessed STV online communities or SNS, and requested survey. For paper-based survey, we gathered random data from people on the streets. 
The ratios of male to female respondents were $57.4 \%$ and $42.6 \%$, respectively. Age groups consisted of those in their twenties (51.9\%), thirties (18.9\%), forties $(18.9 \%)$, and fifties $(10.3 \%)$. In terms of occupation, respondents were mainly undergraduate and graduate students $(47.6 \%)$ and full-time company employees employed (43.4\%), followed by elected public officials, self-employed individuals, and others. In terms of TV habits, among the 212 respondents surveyed, 98 (46.2\%) use video-on-demand (VOD) service, 19 (8.9\%) use other applications, $18(8.5 \%)$ use STV as smart hub to control other devices, and 77 (36.4\%) simply prefer to watch TV.

We assessed the level of non-response bias by comparing early and late respondents, i.e., those who replied during the first week and those who replied during the last week. According to the method proposed by Armstrong and Overton (1977), t-tests were conducted with regard to each case, showed that the early and late respondents did not differ significantly in terms of their gender, age, or occupation.

\section{RESULTS}

Data analysis was conducted using the structural equation modeling technique of partial least squares (PLS) with SmartPLS 2.0. PLS is primarily intended for causal-predictive analysis in situations of high complexity (Barclay, Higgins and Thompson, 1995). PLS is suitable for examining a model when it is expanded by adding new factors to an existing theoretical model to reflect circumstances connected to emerging technology with potential customers and a rapidly growing market (Henseler, Ringle and Sinkovics, 2009). Also, PLS is not as restrictive on the sample as multivariate normal data distributions, and scales may be ordinal (Chin, Marcolin and Newsted, 2003). We first assessed the validity of the measurement instrument and then tested the hypotheses.

To validate the instrument conceptually, six innovation management researchers and four R\&D researchers reviewed the measurement items and examined their validity. Before statistically testing the measurement model, we checked for possible common method variance (CMV). As with all self-reported data, there is a potential for common method biases that can lead erroneous results. Harman's single-factor test was employed to examine whether a single factor accounted for a majority of the variance in the data (Podsakoff et al., 2003). The single-factor test results do not indicate that a single-factor accounts for the majority of the variance, suggesting CMV was not a serious problem.

Next, we further examined the constructs for convergent and discriminant validity. Convergent validity can be established by the following criteria: (1) the factor loadings of items should be significant and should exceed 0.7 , (2) the composite reliability (CR) and Cronbach's $\alpha$ should exceed 0.7 , and (3) the average variance extracted (AVE) of the constructs should exceed 0.50 (Fornell and Larcker, 1981). As shown in Tab. 2, the standardized path loadings of all 
items were significant ( $\mathrm{t}$ values $>1.96$ ) and greater than 0.7 . The $\mathrm{CR}$ and Cronbach's $\alpha$ for all constructs exceeded 0.7. The AVE for each construct was greater than 0.5. Therefore, the measures show good convergent validity as shown in Tab. 2.

Table 2 - Convergent Validity

\begin{tabular}{|l|c|c|c|c|}
\hline Variables & Factor Loadings & AVE & CR & Cronbach's $\alpha$ \\
\hline ITU & $0.899,0.923,0.838$ & 0.788 & 0.917 & 0.864 \\
\hline PUSE & $0.858,0.782,0.850,0.867$ & 0.705 & 0.905 & 0.860 \\
\hline PENJ & $0.933,0.929,0.897$ & 0.847 & 0.943 & 0.909 \\
\hline SOCI & $0.915,0.928,0.928$ & 0.853 & 0.946 & 0.914 \\
\hline INT & $0.894,0.832,0.787$ & 0.703 & 0.877 & 0.791 \\
\hline CONQ & $0.826,0.915,0.905$ & 0.779 & 0.913 & 0.858 \\
\hline SIM & $0.857,0.929,0.923$ & 0.816 & 0.930 & 0.888 \\
\hline
\end{tabular}

Notes: ITU - Intention to use STV, PUSE - Perceived usefulness, PENJ - Perceived enjoyment, SOCI - Social influence, INT - Interactivity, CONQ - Content quality, SIM - Simplicity

Discriminant validity is assessed using the guideline suggested by Fornell and Larcker (1981) in which the square root of AVE for each construct should exceed the correlation between that and any other construct. Tab. 3 lists the correlation matrix, with the correlations among the constructs and the square root of AVE shown diagonally. The diagonal values exceed the inter-construct correlations; hence, the result of the test of discriminant validity is acceptable.

Table 3 - Discriminant Validity

\begin{tabular}{|c|c|c|c|c|c|c|c|}
\hline & CONQ & PENJ & ITU & SIM & PUSE & INT & SOCI \\
\hline CONQ & $\mathbf{0 . 8 8 3}$ & & & & & & \\
\hline PENJ & 0.523 & $\mathbf{0 . 9 2 0}$ & & & & & \\
\hline ITU & 0.475 & 0.551 & $\mathbf{0 . 8 8 7}$ & & & & \\
\hline SIM & 0.296 & 0.378 & 0.408 & $\mathbf{0 . 9 0 3}$ & & & \\
\hline PUSE & 0.591 & 0.520 & 0.639 & 0.393 & $\mathbf{0 . 8 4 0}$ & & \\
\hline INT & 0.339 & 0.330 & 0.428 & 0.257 & 0.386 & $\mathbf{0 . 8 3 8}$ & \\
\hline SOCI & 0.408 & 0.438 & 0.607 & 0.315 & 0.517 & 0.311 & $\mathbf{0 . 9 2 4}$ \\
\hline
\end{tabular}

Notes: Leading diagonal shows the squared root of AVE of each construct

With an adequate measurement model and an acceptable level of multicollinearity, we tested the hypotheses using PLS. Fig. 2 presents the results 
of the PLS structural model assessment with the overall explanatory power $\left(\mathrm{R}^{2}\right)$ and estimated path coefficients. Tests of significance of all paths were performed using the bootstrap resampling procedure.

As a test of hypotheses, PUSE (coefficient $(\beta=0.33)$, PENJ $(\beta=0.20)$, SOCI $(\beta=0.32)$, and SIM $(\beta=0.10)$ have significant effects on the ITU at $\mathrm{p}<0.01, \mathrm{p}<0.05, \mathrm{p}<0.01$, and $\mathrm{p}<0.05$, respectively. Thus, $H 1, H 2, H 3$, and $H 10$ are supported. INT $(\beta=0.17)$, CONQ $(\beta=0.47)$, and $\operatorname{SIM}(\beta=0.21)$ have significant effects on perceived usefulness at $p<0.01$. Also, CONQ $(\beta=0.47$ on PENJ, and INT $(\beta=0.31)$ on SOCI are statistically significant at $\mathrm{p}<0.01$. Therefore, $H 4, H 6$, $H 7, H 7$, and $H 9$ are supported. Only the path coefficients of INT to PENJ is insignificant ( $H 5$ was rejected).

The results of the PLS analysis about the explanatory power $\left(\mathrm{R}^{2}\right)$ show that $56 \%$ of the variance in the intention to use STV was explained by the proposed research model; $43 \%$ of the variance in perceived usefulness, $30 \%$ of the variance in perceived enjoyment, and $11 \%$ of the variance in social influence was explained.

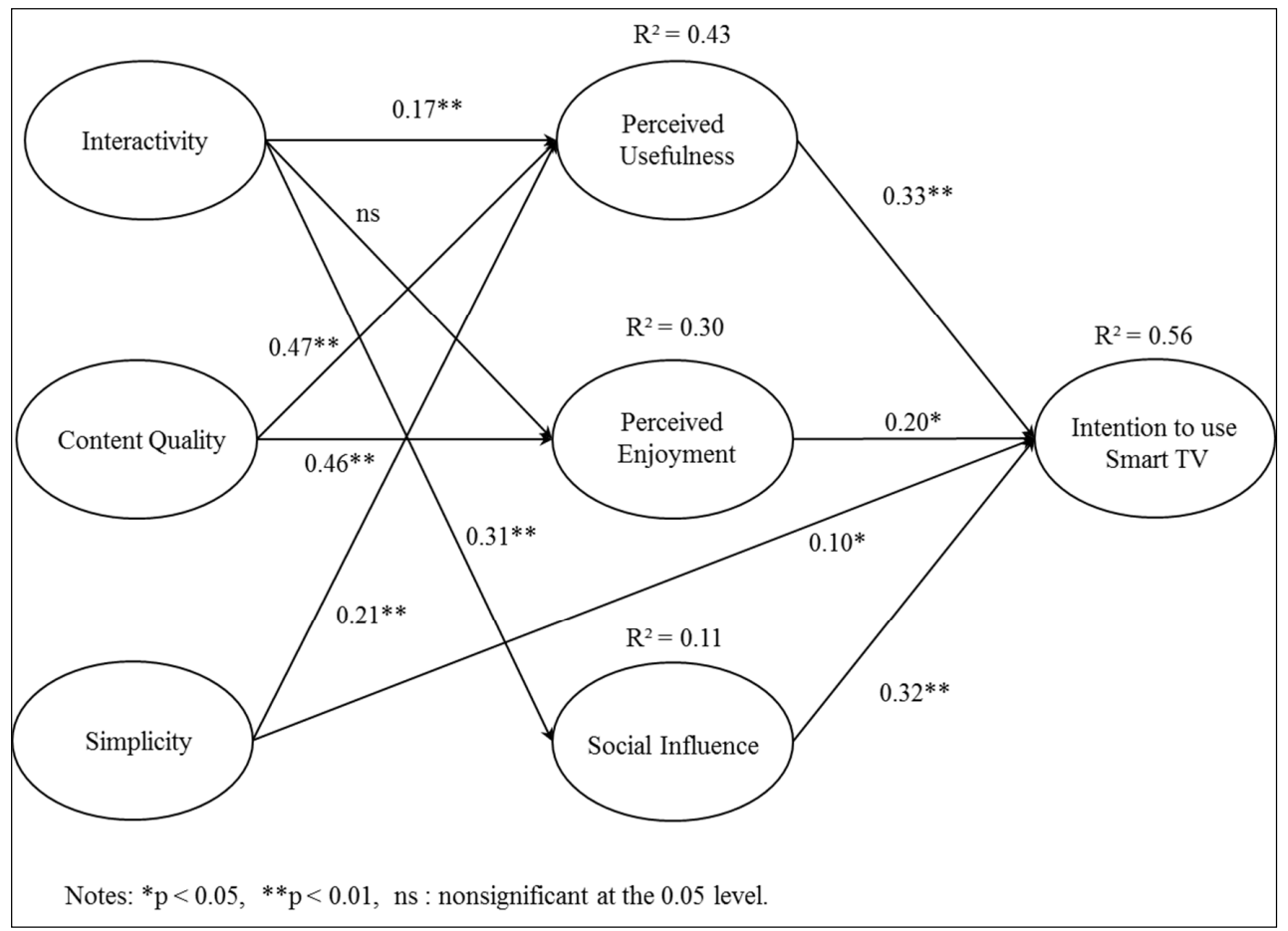

Figure 2 - Results of the Hypotheses Tests 


\section{DISCUSSION AND IMPLICATIONS}

The goal of the study was to empirically identify importance of service for market growth of STV by understanding consumer perception and intention for use of STV services. Our results contain several important findings.

First, STV services including interactivity, high content quality, and simple service process provide relative advantages such as social, educational, informational, and commercial functions that are not offered by conventional TV (Bae and Chang, 2012). In particular, STV is likely to evolve as a social platform given its interactivity, which enables users to connect to online communities or social media. Thus, we empirically identified the service advantages offered by interactivity lead to the lean-forward use of STV due to the perception of it being more useful, enjoyable, and social than conventional TV.

Second, the main reason that current consumers make passive use of STV could be the lack of content that takes full advantage of the benefits of STV. Our study provides empirical analyses to support this point by identifying the quality of content from STV may clearly draw more users' attention and thus effectively influence users' intentions to use STV further. When considering our statistical results, content quality is more important to increase the value of STV than interactivity or simplicity in current STV context.

Third, with respect to simplicity, given that consumers lean back while watching conventional $\mathrm{TV}$, it is difficult to expect consumers to actively learn complex and difficult services of STV. Therefore, a simple and intuitive service interface will allow consumers to perceive the usefulness of the various services offered by STV.

Lastly, our findings indicate that perceived usefulness, perceived enjoyment, and social influence act as key indicators of the intention to use STV. Statistical analyses supported independent variables indirectly influence the intention to use STV through these key indicators. We also conducted post-hoc analysis to statistically identify mediating effect of that perceived usefulness, perceived enjoyment, and social influence. The post-hoc results show that the effect of content quality on intention to use STV is fully mediated by perceived usefulness, while interactivity and simplicity are partially mediated by perceived usefulness. Perceived enjoyment and social influence also partially mediates the relationship between antecedents and intention to use STV. The results are consistent with earlier work that used TAM to reflect the characteristics of a hedonic system (Shin, 2009), indicating that our extended TAM is still valid when it is used to explain and predict user behavior in the STV context.

This study makes several important contributions. First, this study focuses on perspectives of service dominant logic: how customers perceive and use STV and, how STV service factors play a role in the development of customer's intention to use. This study contributes theoretical foundations to future research 
on smart devices by developing service and consumer oriented research model, unlike previous research that has primarily focused on R\&D side of STV.

Second, dealing with the importance of services for active and continuous use and adoption of STV, this study proposed interactivity, content quality, and simplicity as service characteristics of STV. We expanded the concept of interactivity in the STV to include constantly communicating with other users as well as interaction with the STV services. Also, the concept of content quality was expanded to cover not only simple information quality but also customized service quality about usefulness, enjoyment, and sociality that consumer expect from STV.

These key factors used in this study can be essential and meaningful factors for future research that deal with social platform or smart devices by finding the consumer service needs and understanding the psychological process for enduser acceptance and continuous use of them.

The findings of our study offer several practical implications for STV manufacturers as well as platform and content providers.

First, high quality content from various programs and applications is necessary to increase the level of usefulness, pleasure, and sociality of STV. Then, how to establish the STV ecosystem to provide high quality contents? Similar to current STV ecosystem, content of smartphone in the early stage was distributed in close platform by smartphone manufacturers and mobile service provider, so market size was not large enough to provide high quality content.

At this time, apple and android application stores gave third-party providers motivation to develop various applications to attract consumers and make profit. These application distribution channels help mobile phone market to establish successful smartphone ecosystem by releasing various high quality contents. In other words, the successful case of smartphone application markets shows that high quality contents may not arise solely from the efforts of platform companies or manufactures.

Various content providers should participate in producing high quality content. To realize such participation, the STV industry should establish a distribution structure that generates sufficient profits for content providers as done in smartphone market. As the current STV interfaces are not suitable for conducting complex work that can be performed on a personal computer, STV should focus on providing simple but necessary information and services to foster efficiency.

Second, to emphasize the differences between conventional TV and STV, interactivity should be highlighted. Services should be provided to allow twoway communication and to allow users to engage in active interactions with other users. In other words, it is important to provide interactive entertainment elements or on-demand information elements that match the main TV contents. Such advantages will attract people to use STV by giving them dynamic interactivity. 
Despite its significant practical and theoretical implications, this study has some limitations. First, we only collected sample data from real users in Korea. Consumer perceptions and their influence on intention may differ from culture to culture. Moreover, because young and well-educated consumers constitute the majority of the respondents here, it is difficult to generalize the findings to all age groups. It would be useful to test the robustness of these results further by replicating the study across multiple cultures and various consumer age groups.

Second, this study was limited by the fact that the STV service is itself limited. STV is still in its infancy, and the services and applications through which consumers may sufficiently experience and perceive the merits of STV are limited. They responded to our questions after using only a few such services. As STV technology and services gets sophisticated, the perceived level of usefulness by consumers may evolve.

\section{REFERENCES}

Abroud, A., Choong, Y.V., Muthaiyah, S. and Fie, D.Y.G., 2015. Adopting efinance: decomposing the technology acceptance model for investors. Service Business, [e-journal] 9(1), pp.161-182. 10.1007/s11628-013-0214-X.

Ajzen, I., 1991. The Theory of Planned Behavior. Organizational Behavior and Decision Processes, [e-journal] 50(2), pp.179-211. 10.1016/07495978(91)90020-T.

Al-Jabri, I.M. and Sohail, M.S., 2012. Mobile banking adoption: Application of diffusion of innovation theory. Journal of Electronic Commerce Research, 13(4), pp.379-391.

Armstrong, J.S. and Overton, T.S., 1977. Estimating nonresponse bias in mail surveys. Journal of marketing research, 14, pp.396-402.

Bae, Y. and Chang, H., 2012. Adoption of smart TVs: a Bayesian network approach. Industrial Management \& Data Systems, 112(6), pp.891-910.

Barclay, D., Higgins, C. and Thompson, R., 1995. The partial least squares (PLS) approach to causal modeling: personal computer adoption and use as an illustration. Technology Studies, 2(2), pp.285-309.

Bere, A., 2014. Exploring determinants for mobile learning user acceptance and use: An application of UTAUT. ITNG 2014, Proceedings of the 11th International Conference on Information Technology: New Generations. Las Vegas, NV, USA, 07-09 April 2014. Washington, DC, USA: IEEE Computer Society. pp.84-90.

Briel, R., 2012. Philips launches new smart TV experience. Broadband TV News, [online]. 27 February 2012. Available at: $<$ http://www.broadbandtvnews.com/2012/02/27/philips-launches-new-smart-tvexperience/> [Accessed 09 October 2015]. 
Cesar, P. and Chorianopoulos, K., 2009. The evolution of TV systems, content, and users toward interactivity. Foundations and Trends in Human-Computer Interaction, [e-journal] 2(4), pp.373-395. 10.1561/1100000008.

Cheng, Y.-H. and Yeh, Y.-J., 2011. Exploring radio frequency identification technology's application in international distribution centers and adoption rate forecasting. Technological Forecasting and Social Change, [e-journal] 78(4), pp.661-673. 10.1016/j.techfore.2010.10.003.

Cheong, J.H. and Park, M.C., 2005. Mobile internet acceptance in Korea. Internet Research, 15(2), pp.125-140. 10.1108/10662240510590324.

Chin, W.W., Marcolin, B.L. and Newsted, P.R., 2003. A partial least squares latent variable modeling approach for measuring interaction effects: Results from a Monte Carlo simulation study and an electronic-mail emotion/adoption study. Information Systems Research, [e-journal] 14(2), pp.189-217. 10.1287/isre.14.2.189.16018.

Davis, F.D., 1989. Perceived usefulness, perceived ease of use, and user acceptance of information technology. MIS Quarterly, [e-journal] 13(3), pp.319339. $10.2307 / 249008$.

Delone, W.H. and McLean, E.R., 1992. Information systems success: the quest for the dependent variable. Information Systems Research, [e-journal] 3(1), pp.60-95. 10.1287/isre.3.1.60.

Fornell, C. and Larcker, D.F., 1981. Evaluating structural equation models with unobservable variables and measurement error. Journal of Marketing Research, [e-journal] 18(1), pp.39-50. 10.2307/3151312.

Gao, Y., Li, H. and Luo, Y., 2015. An empirical study of wearable technology acceptance in healthcare. Industrial Management \& Data Systems, [e-journal] 115(9), pp.1704-1723. 10.1108/IMDS-03-2015-0087.

Grobart, S., 2013. Smart TV Sales Don't Mean Smart TV Use. Bloomberg, [online] 03 May 2013. Available at: $<$ http://www.businessweek.com/articles/2013-05-03/smart-tv-sales-dont-meansmart-tv-use > [Accessed 26 May 2016].

Ha, I., Yoon, Y. and Choi, M., 2007. Determinants of adoption of mobile games under mobile broadband wireless access environment. Information \& Management, [e-journal] 44(3), pp.276-286. 10.1016/j.im.2007.01.001.

Henseler, J., Ringle, C.M. and Sinkovics, R.R., 2009. The use of partial least squares path modeling in international marketing. New challenges to international marketing, 20, pp.277-319.

Hodgkins, K., 2011. Nielsen/Yahoo: $86 \%$ of mobile users fire up their phone while watching TV. IntoMobile, [online] 29 January 2011. Available at: $<$ https://www.intomobile.com/2011/01/29/nielsenyahoo-86-of-mobile-users-fireup-their-phone-while-watching-tv/> [Accessed 26 May 2013]. 
Hoelzel, M., 2014. Smart TVs Are On Pace To Take Over The Entire TV Market. BusinessInsider, [online] 26 July 2014. Available at: $<\mathrm{http} / / / \mathrm{www}$.businessinsider.com/smart-tvs-are-on-pace-to-take-over-the-entiretv-market-2014-7> [Accessed 30 May 2015].

Hong, W., Chan, F.K., Thong, J.Y., Chasalow, L.C. and Dhillon, G., 2013. A framework and guidelines for context-specific theorizing in information systems research. Information Systems Research, [e-journal] 25, pp.111-136. 10.1287/isre.2013.0501.

Kim, B. and Oh, J., 2011. The difference of determinants of acceptance and continuance of mobile data services: A value perspective. Expert Systems with Applications, [e-journal] 38(3), pp.1798-1804. 10.1016/j.eswa.2010.07.107.

Kim, K., Ahn, C. and Hong, J., 2010. Research of Social TV service technology based on smart TV platform in next generation infrastructure. ICCIT (Computer Sciences and Convergence Information Technology), 5th International Conference on Computer Sciences and Convergence Information Technology. Seoul, South Korea, 30 November - 02 December 2010. IEEE.

Kim, M.-W., Kim, E.J., Song, W.M., Song, S.Y., Khil and A.R., 2012. Efficient recommendation for smart TV contents. In: S. Srinivasa and V. Bhatnaga, eds. 2012. Big Data Analytics. Berlin: Springer. pp.158-167.

Lee, M.K., Cheung, C.M. and Chen, Z., 2007. Understanding user acceptance of multimedia messaging services: An empirical study. Journal of the Association for Information Science and Technology, [e-journal] 58(13), pp.2066-2077. 10.1002/asi.20670.

Lin, J.Ch.-Ch. and Lu, H., 2000. Towards an understanding of the behavioural intention to use a web site. International Journal of Information Management, [ejournal] 20(3), pp.197-208. 10.1016/S0268-4012(00)00005-0.

Lucia-Palacios, L., Përez-Lõpez, R. and Polo-Redondo, Y., 2016. Enemies of cloud services usage: inertia and switching costs. Service Business, [e-journal] 10(2), pp.447-467. 10.1007/s11628-015-0277-y.

Mallat, N., 2007. Exploring consumer adoption of mobile payments - A qualitative study. The Journal of Strategic Information Systems, [e-journal] 16(4), pp.413-432. 10.1016/j.jsis.2007.08.001.

Martïnez-Torres, M., Dïaz-Fernãndez, M., Toral, S. and Barrero, F., 2015. The moderating role of prior experience in technological acceptance models for ubiquitous computing services in urban environments. Technological Forecasting and Social Change, [e-journal] 91, pp.146-160. 10.1016/j.techfore.2014.02.004. 
Murschetz, P. and Evens, T., 2013. Smart TV in Germany: how does convergence impact market structure industry and business model venturing in digital television broadcasting?. 6th Conference of the International Media Management Academic Association. Lisabon, Spain. pp.1-31.

Park, J.-H. and Kim, M.K., 2016. Factors influencing the low usage of smart TV services by the terminal buyers in Korea. Telematics and Informatics, [e-journal] 33(4), pp.1130-1140. 10.1016/j.tele.2016.01.001.

Podsakoff, P.M., Mackenzie, S.B., Lee, J.Y. and Podsakoff, N.P., 2003. Common method biases in behavioral research: a critical review of the literature and recommended remedies. Journal of Applied Psychology, [e-journal] 88(5), pp.879. 10.1037/0021-9010.88.5.879.

Premkumar, G. and Roberts, M., 1999. Adoption of new information technologies in rural small businesses. Omega, [e-journal] 27(4), pp.467-484. 10.1016/S0305-0483(98)00071-1.

Shang, R.A., Chen, Y.C. and Shen, L., 2005. Extrinsic versus intrinsic motivations for consumers to shop on-line. Information \& Management, [ejournal] 42(3), pp.401-413. 10.1016/j.im.2004.01.009.

Shin, D.H., 2009. An empirical investigation of a modified technology acceptance model of IPTV. Behaviour \& Information Technology, [e-journal] 28(4), pp.361-372. 10.1080/01449290701814232.

Shin, D.H., Hwang, Y. and Choo, H., 2013. Smart TV: are they really smart in interacting with people? Understanding the interactivity of Korean Smart TV. Behaviour \& Information Technology, [e-journal] 32(2), pp.156-172. 10.1080/0144929X.2011.603360.

Sonnenwald, D.H., Maglaughlin, K.L. and Whitton, M.C., 2001. Using innovation diffusion theory to guide collaboration technology evaluation: Work in progress. WET ICE, Proceedings Tenth IEEE International Workshop on Enabling Technologies: Infrastructure for Collaborative Enterprises. Cambridge, MA, USA, 20-22 June 2001. IEEE. pp.114-119.

Tsai, P.H. and Chang, S.C., 2013. Comparing the Apple iPad and non-Apple camp tablet PCs: A multicriteria decision analysis. Technological and Economic Development of Economy, [e-journal] 19(1), pp.S256-S284. 10.3846/20294913.2013.881929.

Van der Heijden, H., 2004. User acceptance of hedonic information systems. MIS Quarterly, 28(4), pp.695-704. 10.2307/25148660.

Vargo, S.L. and Lusch, R.F., 2004. Evolving to a new dominant logic for marketing. Journal of marketing, [e-journal] 68(1), pp.1-17. 10.1509/jmkg.68.1.1.24036. 
Venkatesh, V., Morris, M.G., Davis, G.B. and Davis, F.D., 2003. User acceptance of information technology: Toward a unified view. MIS Quarterly, [ejournal] 27(3), pp.425-478. 10.2307/30036540.

Verkasalo, H., Lõpez-Nicolãs, C., Molina-Castillo, F.J. and Bouwman, H., 2010. Analysis of users and non-users of smartphone applications. Telematics and Informatics, [e-journal] 27(3), pp.242-255. 10.1016/j.tele.2009.11.001.

Wixom, B.H. and Todd, P.A., 2005. A theoretical integration of user satisfaction and technology acceptance. Information Systems Research, 16(1), pp.85-102.

Wu, J.H. and Wang, S.-C., 2005. What drives mobile commerce?: An empirical evaluation of the revised technology acceptance model. Information \& Management, [e-journal] 42(5), pp.719-729. 10.1016/j.im.2004.07.001.

Yeh, C.C., 2015. Using a hybrid model to evaluate development strategies for digital content. Technological and Economic Development of Economy, [ejournal] 23(6), pp.1-15. 10.3846/20294913.2015.1071293.

Yu, E., Hong, A. and Hwang, J., 2016. A socio-technical analysis of factors affecting the adoption of smart TV in Korea. Computers in Human Behavior, [ejournal] 61, pp.89-102. 10.1016/j.chb.2016.02.099.

Zhou, T., 2013. Understanding continuance usage of mobile sites. Industrial Management \& Data Systems, [e-journal] 113(9), pp.1286-1299. 10.1108/IMDS01-2013-0001.

\section{ABOUT AUTHORS}

Insu Cho - Assistant Professor, Department of Industrial and Management Engineering, Sun Moon University, Republic of Korea. E-mail: incho@sunmoon.ac.kr, Author's ORCID: 0000-0001-6322-638X.

Jong Ho Lee - Corresponding Author, Ph.D. Candidate, Department of Industrial Engineering, Yonsei University, Republic of Korea. E-mail: kjhlee@yonsei.ac.kr, Author's ORCID: 0000-0003-4032-6841.

Young Hoon Kwak - Associate Professor, Department of Decision Sciences, The George Washington University, USA. E-mail: kwak@gwu.edu, Author's ORCID: /0000-0003-3042-4130.

Conflicts of Interest: The authors declare no conflict of interest.

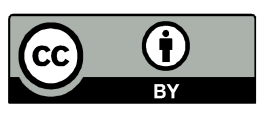

(C) 2019 by the authors. Submitted for possible open access publication under the terms and conditions of the Creative Commons Attribution (CC-BY) license (http://creativecommons.org/licenses/by/4.0/). 